

\title{
A foto jornalística como discurso e campo fértil de produção de sentidos*
}

\author{
The journalistic photo as discourse and fertile field of \\ meaning production
}

Janaina Dias Barcelos*

\begin{abstract}
Resumo: Este artigo apresenta parte das discussões teóricas da tese "Imagem e produção de sentido sobre favelas cariocas em fotos jornalísticas", ao retomar o debate sobre o caráter aparentemente objetivo da foto e o risco de assimilar-se o visto sem considerar seus elementos culturais e ideológicos, para pensar sobre o discurso fotojornalístico e os sentidos que ele pode engendrar, direcionando o olhar para determinadas visões de mundo.
\end{abstract}

Palavras-chave: Fotojornalismo. Discurso. Verdade. Produção de sentidos.

Abstract: This paper presents part of the theoretical discussions on the thesis "Image and sense production about Rio de Janeiro favelas in journalistic photos", retaking the argument about the apparently objective character of the photo and the risk of assimilating the image without considering its cultural and ideological elements, to consider the photojournalistic discourse and the meanings that it can engender, directing the gaze to certain worldviews.

Keywords: Photojournalism. Discourse. Truth. Sense production.

* A tese foi desenvolvida com bolsa CAPES.

** Doutora em Estudos Linguísticos pela Universidade Federal de Minas Gerais (UFMG), com bolsa sanduíche na Université Paris-Est Cretéil, e mestre em Comunicação - Jornalismo pela Universidade de Coimbra, Portugal. Professora adjunta do Departamento de Comunicação Social da Universidade Federal do Rio Grande do Norte (DECOM/UFRN). 


\section{Introdução}

Refletir quais os possíveis sentidos engendrados pelo discurso de fotos jornalísticas é um desafio. Para pensar em caminhos que nos orientem nessa trajetória, é preciso considerar a complexidade dessa prática social, bem como dos discursos que tais imagens constroem, que visão de mundo apresentam, mobilizando quais imaginários.

As imagens fotojornalísticas consistem em uma entre várias práticas de se ver e contar a realidade, podendo ser compreendidas como um gênero de discurso da imprensa que seleciona e organiza os fatos do mundo em enquadramentos que contam uma história, proporcionam informação sobre algum acontecimento. As observações de Tavares e Vaz (2005) sobre a prática jornalística podem ser direcionadas, nesse sentido, para a compreensão da prática fotojornalística:

Os acontecimentos para os quais se volta a prática jornalística encontram-se (des) organizadamente dispostos na realidade social, mas não são vazios de sentido. Eles incorporam formas e visões de mundo; corporificam tempos e espaços que lhes são também externos e anteriores; sem, no entanto, deixar de envolvê-los. Assim, o jornalista, como "narrador profissional", faz convergir para uma esfera de comunicação especializada uma série de elementos já dispostos na trama comunicativa do cotidiano. Nesse sentido, o jornalismo é uma prática especializada, uma forma profissional de narrar o mundo e as várias outras narrativas que dele fazem parte (TAVARES; VAZ, 2005, p. 228). 
Desse modo, o fotojornalismo se especializaria em enunciar o mundo visualmente. Além de conter informações, a foto jornalística produz algum tipo de conhecimento sobre as coisas e as pessoas do mundo, bem como abarca visões sobre esse mundo retratado (e recortado). Como aponta Dubois (1992), a fotografia é um ato icônico, inseparável de sua enunciação, implica a questão do sujeito em processo. Ou seja, é um ato de comunicação que pressupõe interlocutores em dada situação na construção de um discurso visual. É gênero e é discurso.

É nesse sentido que compreendemos a afirmação de Besnard (2005), ao pensar sobre o papel da fotografia na imprensa de que a foto, em si, não informa; ela porta, sim, um discurso sobre a informação, como também afirma Charaudeau (2010a, p. 36): "A informação é pura enunciação. Ela constrói saber e, como todo saber, depende ao mesmo tempo do campo de conhecimentos que a circunscreve, da situação de enunciação na qual se insere e do dispositivo no qual é posta em funcionamento".

Nessa troca comunicativa para informar, o fotojornalista poderá recorrer, por exemplo, a elementos da linguagem fotográfica, como enquadramento, composição, entre outros; os quais colaborem para que ele construa uma imagem que transmita as intenções de informações que deseja. Precisamos ainda levar em conta que as fotos são publicadas em determinado veículo da imprensa, a qual também possui seu projeto de fala, que selecionará as imagens que chegarão ao público a partir de dada finalidade. Não se pode desconsiderar, também, o papel da instância receptora, que atua como coconstrutora dos sentidos do discurso.

Feita essa introdução, propomos aqui duas reflexões: 
retomar, em um primeiro momento, o debate no campo do jornalismo e do discurso, sobre o caráter aparentemente objetivo da foto e do risco de assimilar-se o visto sem considerar elementos outros que a perpassam, como os culturais e ideológicos; para, então, debruçarmo-nos sobre algumas considerações acerca da produção de sentidos nesse campo fértil da produção visual bidimensional.

\section{Muito Além de um Espelho}

Inicialmente, trazemos a discussão - não nova, porém atual e sempre relevante - sobre o caráter aparentemente objetivo da imagem fotojornalística, que oferece uma ilusão de transparência. Afinal, em seus primórdios, a fotografia estava presa à ideia de imitação, de reprodução do real e só ao longo do tempo, as percepções sobre seu papel foram se modificando e a fotografia foi se libertando das amarras dessa marca inseparável da realidade.

Aindano século XIX, sua difusãoprovocou uma grande comoção no meio artístico, marcadamente naturalista, que via o papel da arte eclipsado pela fotografia, cuja plena capacidade de reproduzir o real, através de uma qualidade técnica irrepreensível, deixava em segundo plano qualquer tipo de pintura. $\mathrm{O}$ caráter de prova irrefutável do que realmente aconteceu, atribuído à imagem fotográfica pelo pensamento da época, transformou-a num duplo da realidade, num espelho, cuja magia estava em perenizar a imagem que refletia (MAUAD, 1996, p. 74).

Essa noção de mimese repercute, ainda hoje, na construção de um discurso fotojornalístico que se pretende credível e verdadeiro. Porém, como bem destaca a autora, sabemos que 
a fotografia ultrapassa seu caráter analógico, pois consiste numa “elaboração do vivido", no "resultado de um ato de investimento de sentido" (MAUAD, 1996, p. 75). Logo, ressaltamos: trata-se de um discurso elaborado por um sujeito, a partir de um intercâmbio comunicativo com outro sujeito, em uma dada situação.

Sabemos que a forte ligação da foto com o referente marca o desenvolvimento do fotojornalismo e, em grande medida, é responsável pelas concepções de prova e testemunho que a acompanham. Essa noção de que a foto não mentiria decorre da própria consciência do processo técnico de produção da imagem fotográfica, já que só pode ser fotografado algo que realmente está lá. Como aponta Barthes (1984, p.115), o referente seria "a coisa necessariamente real que foi colocada diante da objetiva, sem a qual não haveria fotografia"'. É daí que o autor parte para discutir a ideia do "Isso-foi", ou seja, da dupla posição de realidade e passado, de algo que está presente na foto em algum momento do passado, porém que também está ali viva na própria superfície da imagem, em sua materialidade.

Charaudeau $(2008-2009,2013)$ também toca nesse ponto, ao ressaltar que o jogo de semelhança da fotografia tem um caráter autentificador, ratificante, pelo "certificado de presença" que ela carrega, o qual associamos ao "Isso-foi" barthesiano. Além disso, para o autor, o fenômeno da instantaneidade reenviaria o representado à sua própria imanência, que apesar de caracterizar o jogo da dessemelhança, fixa a realidade por meio do representado,

1 Do original em francês: "la chose nécessairement réelle qui a été placée devant l'objective, faute de quoi il n'y aurait pas de photographie". Barthes (1980).

Do original em francês: “ça-a-été”. Barthes (1980). 
presentificando, ao mesmo tempo, o passado e um agora. Consideramos, portanto, que ambos aspectos contribuiriam para essa ideia de testemunho, prova e verdade que acompanha a foto de imprensa desde seu desenvolvimento.

Ao tratar da imagem televisiva, Charaudeau (2010a, p. 110 - 111) lista três efeitos que ela é capaz de suscitar. Pensamos que eles podem ser relacionados à fotografia jornalística também: i) efeito de realidade, "quando se presume que ela reporta diretamente o que surge no mundo"; ii) efeito de ficção, "quando tende a representar de maneira analógica um acontecimento que passou"; iii) efeito de verdade, "quando torna visível o que não era a olho nu". O fotojornalismo busca reportar os acontecimentos do mundo com a força do testemunho, no sentido de que o fotógrafo estava de fato ali na hora do registro. A foto tem caráter analógico, que a cola ao referente, devido ao próprio processo mecânico, apesar de a imagem não ser a coisa; e ele torna visível não apenas aquilo invisível a olho nu, mas sim aquilo a que não temos acesso, aquilo que está distante, aquilo que não vivenciamos diretamente.

No entanto, ao colar-se referente e significado, corre-se o risco de naturalizar a leitura das fotos da imprensa, assimilandose o visto e compreendido sem considerar que a mensagem porta elementos culturais e ideológicos. Joly (2003) levanta essa discussão: por ser tomada do real, a foto de imprensa, bem como sua legibilidade, pode reforçar a ideia de que o mundo é conhecido, reconhecido, compreensível e previsível, fazendo com que o leitor possa crer que aquela imagem é conforme o próprio mundo, um retrato "fiel". Essa ilusão de transparência das imagens midiáticas também é mencionada por Wolf (2004). O autor destaca que além 
da subjetividade atrás da objetiva, há todo um trabalho de mostrar e selecionar, bem como um jogo de interesses e até de acasos, que levam a mostrar algo de um jeito e não de outro.

Charaudeau (2010a) comenta essa ilusão de que a imagem televisiva representaria o mundo como ele é. Trazendo suas reflexões para a fotografia de imprensa, podemos verificar que nela, assim como na tv, o mundo se torna próximo e presente, criando um efeito de autenticidade (eu vi no jornal, eu vi na tv), e até mesmo um efeito de fascinação, que faz com que o público reduza o mundo ao que vê enquadrado. No entanto, enquanto a tv seria "a-contemplativa" (CHARAUDEAU, 2010a, p. 112), a foto possibilitaria certa abertura, uma possibilidade de fixar o olhar, de orientá-lo diante daquela superfície icônica.

Flusser (1998) também destaca o fato de as imagens serem mediações entre o homem e o mundo, as quais substituem eventos por cenas, permitindo-nos vivenciar o mundo a partir desse conjunto de cenas.

O autor também reflete sobre o caráter aparentemente objetivo que acompanha a fotografia, porque o observador confia nas imagens como em seus olhos, mas, quando as critica, o faz enquanto visões de mundo. Isso quer dizer que a objetividade aparente deriva apenas do significado que se imprime de forma automática sobre a superfície das imagens, mas, como elas também são simbólicas, precisam ser decifradas. 'Decifrá-las é reconstituir os textos que tais imagens significam' (Flusser, 1998, p. 34), já que ver imagens técnicas significa ver determinados conceitos relativos ao mundo (BARCELOS, 2009, p. 5).

Em conjunto com esses aspectos, podemos citar a própria deontologia do jornalismo, pretensamente voltada ao interesse 
público, que sustentaria sua credibilidade e lhe conferiria uma espécie de autonomia e liberdade de produzir discursos. Esses princípios acabaram sendo incorporados ao fotojornalismo. Nesse processo, a imprensa constrói determinada visão de mundo, tendo a credibilidade conferida pelo discurso da utilidade pública, evocando, propondo e legitimando temáticas e pontos de vista.

Além disso, acreditamos que dois aspectos apontados por Charaudeau (2010a, p. 49) também contribuem para essa forte ligação com o real e a verdade: o discurso jornalístico pode portar um "valor de verdade", ao apresentar evidências de um fato, mas também um "efeito de verdade", ligado à convicção, a uma credibilidade que determina o direito à palavra do interlocutor e as condições de validade dessa palavra. Esse efeito dependerá da razão que leva o sujeito a informar de quem é esse sujeito e de quais os meios discursivos empregados para conferir autenticidade e verossimilhança aos fatos. Juntando-se a esses aspectos o próprio caráter analógico da foto, sua força de prova e testemunho acaba se consolidando.

A noção de verdade que perpassa a informação jornalística também está ligada à noção de objetividade, pensada, nesse âmbito, como neutralidade do discurso. Apesar de serem ideais basilares da prática jornalística, principalmente quando ela adotou parâmetros industriais de produção, o que os (foto) jornalistas produzem são “mises en représentation" (COPPOLA; CAMUS, 2007, p. 84), é um modo de contar, linguageiramente (verbal ou visualmente), os fatos selecionados.

Ao discutir o papel do fotojornalismo na realidade midiática, Newton (2001) retoma a questão da credibilidade 
advinda da percepção mecânica da câmera, passando pela noção da foto como evidência irrefutável da veracidade do conteúdo, sustentada pelas perspectívas científicas, empíricas e modernistas, bem como pelo movimento do jornalismo no século $\mathrm{XX}$ em direção à objetividade. A autora lembra que a foto como documento de uma evidência começa a perder espaço diante do entendimento crescente da subjetividade da representação visual, porém tal movimento não teria sido suficiente para balançar o solo da razão de ser do fotojornalismo. Para ela, o que abalou foi a tecnologia da imagem digital, ao escancarar a capacidade de manipular o gênero. Não que a manipulação não existisse desde os primórdios da fotografia, mas o processo digital tornou essa possibilidade explícita. Em contrapartida, Newton (2001) acredita que esse movimento contribui para que a prática diária do fotojornalismo eleve seus modelos éticos e que uma boa reportagem visual ainda pode ser a única fonte credível de imagens verdadeiras.

Essa discussão de Newton (2001) abre outro debate mais amplo: compreender o papel da mídia visual na formação de nossa visão de mundo e de nossa própria identidade, cientes de que produzir e usar imagens da realidade é comunicação mediada de maneira positiva ou negativa - e não verdade objetiva. Nesse sentido, ela desenvolve dois conceitos: i) fotojornalismo como o ato de reportar, isto é, reunir informações e transmiti-las; e ii) verdade visual como conhecimento autêntico derivado do que foi visto, verificável, verossímil, confiável. A partir dessa reflexão, a autora aponta que o significado de visual truth amadureceu, passando da ideia de evidência objetiva para reportagem precisa e honesta, mas esse conceito ainda traz complicações. Assim, ela defende que não 
se pode falar em verdade, uma vez que sempre haverá um ponto de vista, mas sim em imagens o mais verdadeiras possível, a partir do discernimento de que é preciso mostrar de maneira precisa e justa, sem recorrer à manipulação, com consciência do potencial da foto para induzir ao erro e desinformar se não for utilizada com responsabilidade.

Interessante notar que, paradoxalmente, a foto de imprensa deveria surpreender por trazer o novo, aquilo que ainda não vimos, o que foi testemunhado; no entanto, ela deve ser, ao mesmo tempo, facilmente reconhecível, pois se inscreve em uma cultura visual com seus modelos e fotos emblemáticas, e, para que a troca comunicativa se efetive, seu discurso deve partilhar universos de saber com os leitores - que configuram um público bem heterogêneo.

Todavia, vale a pena refletir sobre as possíveis consequências da veiculação de imagens assim, por exemplo, nutrir uma visão universalizante do mundo, uma espécie de esquematização da realidade, desconsiderando sua complexidade e ambivalência, como alerta Besnard (2005). O risco é criar uma grade de leitura como se o mostrado fosse o real. Por isso, é de suma importância analisar os discursos construídos por tais imagens e os imaginários que fazem circular, pois as representações sociais que os engendram podem ter efeitos - positivos ou negativos - sobre as opiniões e a sociedade.

\section{Campo Fértil de Produção de Sentidos}

A discussão sobre o caráter de autenticidade que a fotografia confere ao discurso jornalístico nos conduz a outras 
reflexões, a saber, sobre o processo de significação engendrado por essas imagens e os posicionamentos discursivos que daí emergem. Afinal, como bem destaca Porto Alegre (2001), a imagem constrói um campo próprio de significância que pode estabelecer sentidos vários na comunicação pretendida, inclusive diferente do discurso verbal que possa acompanhá-la. A autora aborda a importância de buscar entender a linguagem visual, o seu lugar nas representações e nos sistemas simbólicos:

Vemos, hoje, que o estudo da imagem é fundamental para o entendimento dos múltiplos pontos de vista que os homens constroem a respeito de si mesmos e dos outros, de seus comportamentos, seus pensamentos, seus sentimentos e suas emoções em diferentes experiências de tempo e espaço (PORTO ALEGRE, 2001, p. 76).

Nesse âmbito, ela resgata as contribuições barthesianas, ao apontar como é forte o valor denotativo da fotografia e sua capacidade de mascarar o sentido construído da imagem, devido a seu efeito de real.

Quando abrimos um jornal ou uma revista de informação, a fotografia logo salta aos nossos olhos. Ela carrega mensagens, discursos plenos de sentidos, contém intenções, além de ser o resultado de negociações antes e depois da sua produção, até que seja veiculada. Tavares e Vaz (2005, p. 133) pontuam essa questão, lembrando que cada meio de comunicação possui uma proposta de leitura sobre o mundo e que as fotos de imprensa são "narrativas dotadas de uma mensagem específica e intencionada". 
Em cada publicação há uma espécie de construção própria da realidade. Olhando jornalisticamente para este universo pode-se dizer: em cada um desses veículos há uma tentativa de se circunscrever o real, às vezes buscando dar conta de seu todo - como o fazem (ou tentam fazer) os jornais diários - ou de algum de seus aspectos (caso das revistas especializadas, por exemplo). Desta forma, compete ao leitor olhar para cada um destes veículos dimensionando suas várias facetas, procurando entender a conexão existente entre a(s) realidade(s) da vida cotidiana e as leituras ou as imagens construídas sobre ela(s) nos jornais e revistas que tem sob os olhos (TAVARES; VAZ, 2005, p. 125 - 126).

Isso quer dizer que cada veículo, de acordo com os objetivos que pretende alcançar na troca comunicativa, construirá um discurso sobre a realidade, que privilegiará determinados aspectos em detrimento de outros, pois adotará as estratégias discursivas capazes de lhe oferecer mais chances de concretizar sua visada. Nesse sentido, os autores notam que a mídia teria papel preponderante para situar o homem no mundo e dimensionar suas experiências.

Portanto, enquanto mediações, as fotografias jornalísticas atuariam como pontes entre o acontecimento e oleitor, possibilitandolhe ter acesso a um registro da cena, da ação e dos personagens naquela situação. Além disso, a foto jornalística contribui para uma impressão de realidade, um efeito de real, que no jornalismo, está intimamente ligada à impressão de "verdade", uma vez que a veracidade da informação é uma das premissas da atividade. E é nessa força de realismo que a foto se ampara no imaginário social, como nota Charaudeau (2013). 
Tomemos como exemplo fotografias de favelas do Rio de Janeiro publicadas no jornal O Globo. É provável que grande parte do público alvo do jornal - classes A e B da Região Metropolitana do Rio - jamais tenha estado em alguma delas, mas ele pode imaginar, pressupor o que acontece lá, como vivem as pessoas e quem são os moradores das comunidades a partir do que o veículo mostra. Esse efeito de real da fotografia jornalística pode reforçar a crença de que aquele lugar e aquelas pessoas são tal qual o jornal apresenta. Afinal,

O fotojornalismo torna acessível em imagens a realidade para a qual o jornal se volta, reforçando as palavras e contribuindo para a construção de um imaginário a respeito dos acontecimentos traduzidos como fragmentos metonímicos do mundo pelo jornal, criando também os próprios acontecimentos fotográficos (TAVARES; VAZ, 2005, p. 131).

Assim, ao apontar a câmera para determinado alvo, o fotojornalista cria uma cena informativa, que oferece uma versão imagética da vida cotidiana. Seu ato opera um corte no tempo e no espaço, congelando a cena e separando-a do que a envolve, focalizando no instante selecionado, o que contribui para intensificálo, como discutem os autores.

Em relação a esse mundo construído pela imprensa, àquilo a que temos acesso pelas fotos publicadas, destacamos uma brincadeira que Gervereau (2004) faz conosco em um de seus questionamentos, a fim de levantar a necessidade de os conteúdos midiáticos serem analisados: 
Você conhece Saddam Hussein? Ah bom, você então já o encontrou? Não? Então, você é como eu, você não o conhece. Mas você tem uma ideia sobre ele, como tem uma ideia de como o mundo funciona. Você vive nessa nova ubiquidade perpétua: em sua casa com as representações do planeta. E essas representações condicionam sua maneira de pensar e de agir (GERVEREAU, 2004, p. 159)3.

Assim como não conhecemos, de fato, Saddam Hussein, não conhecemos quase nada do que temos acesso apenas por meio da mídia. E aquilo que nos chega é ainda uma minoria de fatos entre milhares, selecionados por uma minoria e dirigidos a uma maioria, como ressalta o autor. Seu questionamento não põe em causa as imagens em si, mas seu uso, e atenta para a importância de abrir perspectivas para debater a construção de imaginários por meio dos discursos dos meios de comunicação. Entre essas possíveis visões de mundo, o autor alerta para o risco de se edificarem imaginários redutores que estigmatizam.

Ao mencionar um estudo realizado pelo Baromètre Européen des Médias (BEM), Gervereau (2004) aborda que, apesar de as notícias de tv em diferentes partes do planeta apresentarem visões de mundo heterogêneas, os acontecimentos internacionais são percebidos de modo semelhante, a partir do acesso ilimitado a um estoque de imagens elaborado por poucas pessoas, o que provoca produções repetitivas e estereotipadas. Ele revela ainda

3 Tradução livre da autora para:"Vous connaissez Saddam Hussein, vous? Ah bon, vous l'avez recontré alors? Non? Donc, vous êtes comme moi, vous le connaissez pas. Mais vous avez une idée de sur lui, comme vouz avez une idée de la marche du monde. Vous vivez dans cette perpétuelle ubiquité nouvelle: chez vous et avec les représentations de la planète. Et ces représentations conditionnent votre manière de penser e d'agir". 
que a atualidade de continentes inteiros - África, América do Sul, Ásia - é mínima, aparecendo apenas em casos de catástrofes naturais, epidemias, guerras, genocídios. E exemplifica: "Nós não falamos dos amálgamas entre todas as favelas brasileiras ou as town-ships sul-africanas que têm, sabemos, funcionamentos muito diversificados (e de jeito nenhum o mesmo nível de pobreza)" (GERVEREAU, 2004, p. 112) .

Derville(1997) também discute esse olhar simplificador dos meios de comunicação, que recorrem a categorias uniformizantes, ocultando a diversidade de experiências, condições, recursos e perspectivas possíveis; disseminando discursos e imagens estereotipados $^{5}$. Em relação às periferias, o autor verificou que elas são noticiadas quando se configuram palco de acontecimentos dramáticos ou espetaculares. Ele lembra que a triagem dos eventos a serem noticiados já se contrapõe à noção de espelho da realidade e de fidelidade aos fatos, evidenciando que a atualidade é resultado de uma construção, de um mise en forme e um mise en perspective. Ou seja, são escolhas de o que e como mostrar e a partir de qual ponto de vista. Besnard (2005) segue na mesma linha, ao afirmar que as fotos, na mídia, fazem parte de um mise en forme de l'actualité, presidida por uma intenção da publicação.

Complementando esse racioncínio, em Montanola (2007, p. 215), encontramos as expressões mise en forme médiatique,

4 Tradução livre da autora para: "Ne parlons pas des amalgames entre toutes les favelas brésiliennes ou les town-ships sud-africaines qui ont, nous le savons, des fonctionnements très diversifiés (et pas du tout le même niveau de pauvreté)".

5 Preferimos chamar de representações sociais cristalizadas em vez de estereótipos, com base em estudos de Amossy (2006) e Moscovici (2011). 
que para a autora é sinônimo de mise en sens du réel. Nesse caso, ela se refere ao fato de os meios de comunicação construírem o acontecimento de modo a buscar conferir determinado sentido a um recorte do real. Nesse processo, a autora entende que as rotinas jornalísticas promoveriam uma construção partilhada da atualidade, guiada por esquemas de representação, em adequação a expectativas estereotipadas de jornalistas, redações e leitores.

Besnard (2005) também salienta a relevância de se pensar sobre essas visões simplificadoras, pois o olhar do leitor viria acompanhado de um postulado de verdade, uma vez que a foto seria traço e prova de uma realidade na qual se inspirou, apesar de ser também tomada de um conjunto de códigos.

Se o leitor jamais é "virgem" diante de uma imagem, ele não escapa indiferente à sua contemplação. Entre ele e a fotografia se produz uma interação e, como tal, as imagens contribuem para influenciar e orientar suas representações. Uma das questões que se coloca então é a dos efeitos da fotografia sobre a percepção do mundo pelos indivíduos. Ou, quando elas são repetitivas, simplificadoras, caricaturais, quando elas lembram de modo inconsciente imagens já vistas, moldando assim uma grade de leitura rápida dos acontecimentos, que consequências envolvem? (BESNARD, 2005, p. 11) .

6 Tradução livre da autora para: "Si le lecteur n'est pas jamais $<<$ vierge $>>$ face à une image, il ne ressort pas indifférent de sa contemplation. Entre lui et la photographie se produit une interaction et à ce titre, les images contribuent à influencer et orienter ses représentations. Une des questions qui se pose alors est celle des effets de la photographie sur la perception du monde par les indivus. Or, lorsque celles-ci sont répétitives, simplificatrices, caricaturales, lorsqu'elles rappelent de manière inconciente des images dèjá vues, façonnant ainsi une grille de lecture rapide des évènements, quelles conséquences entraînent-elles?". 
Seu comentário mostra que o leitor está inserido numa cultura visual e num contexto e, no processo de interação entre ele e a imagem, uma série de representações é compartilhada, de modo a elaborar - e mesmo orientar - uma maneira de olhar para o mundo representado. Por trás desse mostrar, existe uma intenção de fazer crer em algo. Diante desse cenário, a autora propõe refletir sobre o que está em jogo, sobre as relações da foto com a apreensão e a compreensão do mundo ${ }^{7}$.

Ao pensar a construção do discurso pela imprensa, Besnard (2005) promove a análise de aproximadamente 300 fotos jornalísticas sobre o conflito no Afeganistão. Seu método buscou debruçar-se sobre o conjunto de imagens para verificar os elementos mais recorrentes a fim de estudar suas representações. O trabalho mostrou que muitas delas são simplificadoras, globalizantes, tornando-se simbólicas de um conjunto de situações que representam sofrimento, pobreza, liberdade, etc. Além disso, percebeu regularidades, nas quais as fotos acabam por classificar e qualificar determinados grupos de personagens, configurando figuras-tipo simbólicas (a vítima, o mal, o modelo, o inimigo, etc.) que direcionam a leitura, geralmente em correlação com uma dada ideologia. A autora concluiu que a foto pode ser empregada como meio de conduzir a interpretação e estimular um imaginário. Nesse sentido, alerta para o fato de que, apesar de ser impossível mostrar em imagens tudo sobre um acontecimento, é necessário reconhecer a autonomia da foto como escritura, mas, igualmente, os seus

7 Em seu livro, a autora trabalha com a relação texto-imagem para pensar como os signos orientam uma interpretação. Seu estudo foca na análise de conteúdo de fotos em quatro meses de cobertura do conflito afegão, feita por quatro jornais. 
limites. É preciso, portanto, tomá-la pelo que ela é: um instante, um corte no espaço e no tempo, que veicula representações as quais são integrantes da informação produzida pelo veículo.

Cros e Soulé (2011) destacam a relevância de pensar as imagens de informação como parte de nosso universo de referências, assim como o verbal e o oral. Os autores classificam o fotojornalismo em três âmbitos: o do acontecimento, com a cobertura da atualidade e a reportagem dos fatos; o documental, que busca comentar a informação, instruir; e o antropológico, que registra imagens da sociedade humana. Classificações como essas são interessantes para a compreensão do objeto de estudo, no entanto, pensamos que a foto de imprensa, em sua complexidade, não pode simplesmente se encaixar numa categoria estanque, podendo ser perpassada em alguma medida por todos esses aspectos. Seja como for, a despeito do fato de o acontecimento ser construído, um elemento deve ser comum: a autenticidade do documento. Caso contrário, romper-seia com o contrato de credibilidade e verossimilhança do discurso jornalístico. Sobre o estatuto das imagens jornalísticas, os autores comentam:

A questão é o próprio estatuto dessas imagens como obras singulares-artísticas e midiáticas. Especialmente quando o discurso sobre as imagens substitui uma verdadeira atenção à sua natureza. Definir o papel da imagem de imprensa como imagem de informação nos remete a analisar os aspectos sociais, culturais, psicológicos e ideológicos que sustentam sua recepção, em relação com os acontecimentos que elas contam. Por outro lado, o testemunho jornalístico, quer passe pela imagem ou pelo texto, permanece, antes de tudo, uma proposição de leitura que vai gerar (ou não) 
um ato de leitura pelo espectador. Toda fotografia resulta de um percurso e constrói um discurso que entra em relação com o percurso e o discurso do espectador (CROS; SOULÉ, 2011, p. 29) ${ }^{8}$.

Com essa citação, os autores destacam a permanência do testemunho jornalístico, porém sem deixar de lado o entendimento de que a imagem passa pela relação entre os interlocutores e com os aspectos sociais, culturais, entre outros, que perpassam essa troca. Ou seja, abordam a imagem de imprensa pelo viés discursivo. Essa noção de testemunho integra a prática jornalística, pois uma espécie de contrato moral liga o veículo a seu público segundo o paradigma ocidental da informação, que pressupõe dizer a verdade. Como o leitor não testemunha os acontecimentos, espera que o jornal o faça e leve os fatos a ele com autenticidade (BESNARD, 2005). Essa expectativa integra a situação de comunicação, pois o macrotema informação é imposto por ela, ainda que o jornal tenha liberdade para tratá-lo da maneira que lhe seja própria. $\mathrm{O}$ interlocutor, por sua vez, espera ver a informação tratada de acordo com a finalidade da situação comunicativa na qual se insere, que seria, predominantemente, o de fazê-lo saber sobre algo.

8 Tradução livre da autora para: "C'est le statut même de ces images comme oeuvres singulières-artistiques et médiatiques - qui fait problème. Surtout lorsque le discours sur les images se substitue à une veritable attention portée à leur nature. Definir la place de l'image de presse comme image d'information revient donc à analyser les aspects sociaux, culturels, psychologiques et idéologiques qui sous-tendent leur réception, em relation avec les événements qu'elles rapportent.

D'autre part le témoignage journalistique, qu'il passe par l'image ou par le texte, demeure avant tout une proposition de lecture qui va générer (ou pas) un acte de lecture de la part du spectateur. Toute photographie resulte d'un parcours et construit un discours qui entre en interaction avec les parcours e le discours du spectateur." 


\section{Construção de Visões de Mundo}

Como temos ciência de que discursos são produzidos a partir de universos de saberes partilhados, que portam representações sociais sobre os grupos aos quais se referem, engendrando imaginários, entendemos que a mídia desempenha importante papel na construção da visão de mundo desses leitores. Apesar de considerarmos que os sujeitos são ativos e o ato de linguagem é um processo de interlocução, sabemos também que o produtor do discurso o construirá a partir de estratégias que lhe confiram mais chances de essa troca se efetivar conforme suas intenções. Como discute Charaudeau (2010b), todo sujeito detém um discurso que o sobredetermina em parte, porém, ao mesmo tempo, busca se posicionar. Nessa tensão, a interpretação do discurso das fotos dependerá do saber de cada leitor e de suas competências discursivas, ao entrar em contato com as estratégias elaboradas pelo locutor para que a troca comunicativa se efetivasse.

O jornal, ao veicular imagens, possui objetivos e sabe o que pretende mostrar. As fotografias jornalísticas não são inocentes: elas traduzem um acontecimento, construindo-o. Recortam uma realidade, são notícia e transmitem informação. Além disso, funcionam, assim como o jornal e seus textos, como mediadoras e peças importantes para a construção de uma imagem (no sentido de um imaginário) sobre algo específico; sobre uma realidade específica (TAVARES; VAZ, 2005, p. 132).

Logo, háumafinalidade aopublicarfotografias jornalísticas. Assim, podemos dizer que, no caso do fotojornalismo em geral, enquanto enunciação, haverá sempre uma intenção; no entanto, 
esta pode ser mais ou menos explícita, de acordo com a situação de comunicação, o contrato que rege a troca, os interlocutores e as estratégias discursivas empregadas. Sobre esse ponto, Charaudeau (2004, p. 25) aponta que "Cada situação de comunicação seleciona, para definir sua finalidade, uma ou várias visadas dentre as quais, geralmente, uma (às vezes duas) é dominante"9. A predominante será aquela que determina a expectativa do contrato de comunicação. No caso do jornalismo, seria o fazer saber.

Dentro da proposta de pensar a fotografia de imprensa como discurso, Cros e Soulé (2011) resgatam a noção de "processus d'événementialisation" 10 apresentada por Charaudeau (2011, p. $82)^{11}$, em que o mise en scéne do fato, no nosso caso, o mise en image, engloba alguns mecanismos:

a) Relatar: inclui o testemunho, o dar a ver algo, documentar, tematizar o mundo, organizar nosso universo de referências; também consiste em identificar e autentificar lugares e pessoas por meio da figuração; e a narratividade, que é contar um fragmento de uma história. Para construir essa narrativa, o fotojornalismo recorre aos elementos da linguagem fotográfica.

b) Comentar: a imagem carrega uma tripla intencionalidade - da foto, do autor e do leitor - e pode ter uma visada ou dimensão argumentativa (AMOSSY, 2006), isto é,

$9 \mathrm{O}$ autor cita as seguintes visadas: prescrição (mandar fazer), solicitação (querer saber), incitação (mandar fazer por meio do fazer acreditar), informação (fazer saber), instrução (fazer saber-fazer) e demonstração (estabelecer a verdade e mostrar as provas). Charaudeau (2004, p. 23 - 24)

$10 \mathrm{Na}$ versão em português do livro, esse conceito foi traduzido como "processo evenemencial". Cf.: Charaudeau (2010a, p. 98).

11 O "processo evenemencial" consiste no movimento de sujeitos que percebem alguma modificação no estado do mundo fenomênico, depreendendo esse acontecimento e inscrevendo sua percepção numa rede coerente de significações sociais. Trata-se do processo de construção do acontecimento. 
apesar de não pretender persuadir, procura direcionar o ponto de vista.

c) Provocar: por meio de recursos dramáticos, patêmicos, a imagem pode tocar as emoções do leitor.

d) Referir: a imagem pode se tornar referência por meio da iconização, de sua capacidade de se tornar ícone com o tempo, devido a seu caráter emblemático, por meio de um processo de condensação e simbolização: e ainda por meio da intericonicidade, da tessitura que se opera entre diferentes imagens que balizam a cultura visual, nossos reflexos de leitura.

Ao passar por esses mecanismos, o valor informacional da foto resultará, segundo Cros e Soulé (2011), de sua iconicidade (o que ela mostra), de sua plasticidade (como ela mostra) e de seu contexto (o mundo que evoca e os textos, imagens e discursos com os quais se articula).

Ainda sobre o caráter informativo, concordamos com o posicionamento de Besnard (2005), o qual já mencionamos, de que a foto de imprensa não informaria, mas portaria um discurso sobre a informação. Isso porque endentemos o ato de comunicação como processo, como co-construção, envolvido em várias interações. Apenas informar nos passa a ideia de transmissão, de enviar uma mensagem de um emissor a um destinatário, proposição tradicional que colaborou para o desenvolvimento do campo, mas já repensada nos estudos do discurso e da comunicação social.

Portanto, como demonstra a autora, a foto não poderia resumir, explicar ou fazer compreender uma situação; entretanto, ela porta sentido, configura um discurso que transborda do objeto, que se revela nos próprios elementos icônicos, e que pode 
se conjugar a outros discursos para reforçar e direcionar uma mensagem. Besnard (2005) vai além: para ela, a foto teria finalidade argumentativa, seria um meio a serviço de uma crença. Apesar desse posicionamento da autora se referir a fotos de guerra - e por isso aparecer de maneira tão contundente -, podemos estender essa reflexão a outros acontecimentos, se consideramos que a própria seleção das imagens já é uma tomada de posição.

Um desses discursos com os quais a foto de imprensa poderia se conjugar seria o verbal. Afinal, outro aspecto a ser pensado no fotojornalismo é a relação entre imagem e texto, a qual pode colaborar para o direcionamento dos sentidos de acordo com a intenção do veículo. Legendas, títulos e reportagens teriam esse papel que Barthes (1990) chama de técnica de fixação, que auxiliaria a dizer o que é aquela cena retratada, conduzindo o sentido e orientando, em alguma medida, a interpretação. A legenda, por exemplo, pode endossar o que a foto mostra; pode modificar inteiramente seu sentido; pode fixar ou realçar significados diante da polissemia da imagem; pode ativar sentimentos ligados à cena.

O fato é que, quando se fala em fotojornalismo, pensase numa combinação de palavras e imagens, numa relação de contextualização e complementariedade. Assim, a própria fotografia seria notícia, discurso de informação, mas também seria contribuição para o significado do texto verbal. Para Sousa (2004), não existe fotojornalismo, enquanto gênero, sem sua relação com o texto verbal. Ele afirma que a imagem fotográfica precisa ser complementada por textos que orientem a construção de sentido e que apenas imagens poderosas poderiam evocar o acontecimento em sua atmosfera. Já Vilches (1993) aponta que, apesar das relações 
entre visual e verbal, o fotojornalismo teria certa autonomia. Ele afirma que, como texto icônico, a foto de imprensa pode ser "visível e legível, adequada e compreensível, sem necessidade de uma legenda ou texto verbal que a acompanhe"12 (VILCHES, 1993, p.71). O que acontece, segundo o autor, é que o leitor de jornal tem expectativas que vão além de ver a imagem. Além disso, ele lembra que a relação entre imagem e texto não é inocente e é muito mais complexa do que sua funcionalidade comunicativa.

Entre algumas das observações interessantes do autor e que têm relação com nossas reflexões, destacamos as seguintes:

1. A foto de imprensa em nenhum momento é mais simples do que o texto escrito. Sua estrutura é complexa, em igual medida, à do texto escrito, e tanto um como o outro são produtos de diversas transformações discursivas. 2. A foto de imprensa não é nem uma ilustração do texto escrito nem tampouco um substituto da linguagem escrita. Tem uma autonomia própria e pode considerar-se como um texto informativo. No entanto, não é indiferente ao contexto espacial do periódico. 3. A foto de imprensa se revela particularmente eficaz em certos processos de reconhecimento e identificação, mas sem negar o mesmo para o texto escrito. 4 . O tipo de processo discursivo que pode desenvolver o estímulo da foto de imprensa pode ser tão abstrato como o desenvolvido pela linguagem escrita. $\mathrm{E}$ isso porque, tanto quanto o texto escrito, ela se baseia em convenções sociais e textuais assumidas pelo leitor, além de complexas elaborações simbólicas ${ }^{13}$ (VILCHES, 1993, p. 77).

12 Tradução livre da autora para: "visible y legible, adecuado y comprensible sin necesidad de una "leyenda" o texto escrito que lo acompañe". 13 Tradução livre da autora para: "1. La foto de prensa en ningún momento es más simple que el texto escrito. Su estructura es compleja en igual medida que lo es el texto escrito, y tanto uno como el outro son productos de diversas transformaciones discursivas. 
Dessa maneira, ele nos aponta a relevância e a autonomia de ambos sistemas de signos, o verbal e o visual, os quais passam por processos discursivos, podem ter caráter informativo, dependem de onde são publicados e de convenções sociais e elaborações simbólicas.

\section{Considerações finais}

Se hoje entendemos o caráter discursivo de uma fotografia de imprensa, nem sempre foi assim. Passando por reflexões que se iniciam na relação da fotografia com a pintura, seguindo pelos caminhos que abordam a ligação da imagem fotográfica com seu referente, bem como sua conexão com o real, até chegar a seu aspecto informativo na prática jornalística, que carrega fortes laços com a noção de testemunho, muito se discutiu e produziu nos campos da comunicação e do discurso.

Nosso percurso nos mostra que o fotojornalismo se configura em um gênero que produz um discurso sobre a informação, mas que, muito além de informar, apresenta visões de mundo que podem orientar, mais ou menos, de forma implícita ou explícita,

2. La foto de prensa no es ni una ilustración del texto escrito ni tampoco una sustitución del lenguaje escrito. Tiene una autonomía propia y puede considerarse como un texto informativo. Sin embargo, no es indiferente al contexto espacial del periódico.

3. La foto de prensa se revela particularmente eficaz en ciertos procesos de reconocimiento e identificación, pero sin negar lo mismo para el texto escrito.

4. El tipo de proceso discursivo que puede desarrollar el estímulo de la foto de prensa puede ser tan abstracto como el desarrollado por el lenguaje escrito. $\mathrm{Y}$ esto se debe a que tanto como el texto escrito se basan en convenciones sociales y textuales asumidas por el lector, además de complejas elaboraciones simbólicas.” 
o nosso olhar. Para isso, pode-se recorrer a estratégias discursivas que procurarão edificar o discurso com a finalidade de se atingir o destinatário de modo a concretizar a troca comunicativa.

Sabemos que os efeitos visados podem não coincidir com os produzidos, principalmente quando se trata de uma comunicação de massa, voltada para um público heterogêneo e vasto. Entretanto, o que nos interessa aqui é sabermos que, na confluência dessas visadas, estão os efeitos possíveis. E é a partir desse ponto que podemos analisar os sentidos possíveis que os discursos de fotos jornalísticas podem engendrar.

\section{Referências}

AMOSSY, Ruth. L'argumentation dans le discours. 2. éd. Paris: Armand Colin, 2006.

BARCELOS, Janaina Dias. Fotojornalismo: dor e sofrimento: estudo de caso do World Press Photo of the year 1955-2008. 2009. 154 f. Dissertação (Mestrado em Comunicação e Jornalismo)

- Faculdade de Letras, Universidade de Coimbra, Coimbra, Portugal, 2009.

BARTHES, Roland. A câmara clara: nota sobre a fotografia. Tradução de Júlio Castañon Guimarães. 2. ed. Rio de Janeiro: Nova Fronteira, 1984.

BARTHES, Roland. A escritura do visível. In: BARTHES, Roland. O óbvio e o obtuso. Tradução de Léa Novaes. Rio de Janeiro: Nova Fronteira, 1990. p. 10-43.

BARTHES, Roland. La chambre claire: note sur la photographie. Paris: Éditions de 1'Étoile: Gallimard: Le Seuil, 1980. p. 120 
BESNARD, Véronique. Mise en images du conflit afghan: rôles et utilisations de la photographie dans la presse internationale. Paris: L'Harmattan, 2005.

CHARAUDEAU, Patrick. Discurso das mídias. Tradução de Angela M. S. Corrêa. 2. ed. São Paulo: Contexto, 2010a.

CHARAUDEAU, Patrick. Imagem, mídia e política: construção, efeitos de sentido, dramatização, ética. In: MENDES, Emília (coord.). Imagem e discurso. Tradução de Emília Mendes e Ivan Vasconcelos Figueiredo. Belo Horizonte: FALE/UFMG, 2013. p. 383-405.

CHARAUDEAU, Patrick. Itinéraires d'un enfant du Collége: les cahiers du collège iconique. Paris: INA, 2008/2009. p. 1-30. (Communications et débats, v. 25).

CHARAUDEAU, Patrick. Les médias et l'information: 1'impossible transparence du discours. 2. ed. Bruxelles: Éditions de Boeck Université: INA, 2011.

CHARAUDEAU, Patrick. Um modelo sociocomunicacional do discurso: entre situação de comunicação e estratégias de individualização. In: PAULA, Luciana; STAFUZZA, Grenissa (org.). Da análise do discurso no Brasil à análise do discurso do Brasil: três épocas histórico-analíticas. Uberlândia: EDUFU, 2010b. p. 259-284.

CHARAUDEAU, Patrick. Visadas discursivas, gêneros situacionais e construção textual. In: MACHADO, Ida Lúcia; MELLO, Renato de (org.). Gêneros: reflexões em análise do discurso. Belo Horizonte: NAD/FALE/UFMG, 2004. p. 13 - 41.

COPPOLA, Vincent; CAMUS, Odile. Le Sida dans la presse: du fait à sa representation. In: BOYER, Henri. Stéréotypage, stereotypes: fonctionnements ordinaires et mises en scène. Paris: 
L'Harmattan, 2007. Tome 1 Média (tisation)s. p. 83-97.

CROS, Marguerite; SOULÉ, Yves. Regarder le monde: le photojournalisme aujourd'hui. Chasseneuil-du-Poitou: CNDP; Paris: CLEMI, 2011.

DERVILLE, Gregory. La stigmatization des "jeunes de banlieue". Communication et Langages, Paris, FR, v. 113, n. 113, p. 104$117,1997$.

DUBOIS, Philippe. O acto fotográfico. Lisboa: Vega, 1992.

FLUSSER, Vilém. Ensaio sobre a fotografia: para uma filosofia da técnica. Lisboa: Relógio D’Água, 1998.

GERVEREAU, Laurent. Inventer l'actualité: la construction imaginaire du monde par les medias internationaux. Paris: La Découverte, 2004.

JOLY, Martine. La interpretación de la imagen: entre memoria, estereotipo y sedución. Barcelona: Paidós Comunicación, 2003.

MAUAD, Ana Maria. Através da imagem: fotografia e história, Interfaces. Tempo, Rio de Janeiro, v. 1, n. 2, p. 73 - 98, 1996. Disponível em: http://www.historia.uff.br/tempo/artigos_dossie/ artg2-4.pdf. Acesso em: 5 out. 2018.

MONTANOLA, Sandy. Représentations et stéréotypes de l'image médiatique des boxeuses de haut niveau. In: BOYER, Henri. Stéréotypage, stereotypes: fonctionnements ordinaires et mises en scène. Paris: L'Harmattan, 2007. Tome 1 Média (tisation)s. p. 215-224.

MOSCOVICI, Serge. Representações sociais: investigações em psicologia social. Tradução de Pedrinho A. Guareschi. 8. ed. Petrópolis: Vozes, 2011. 
NEWTON, Julianne $H$. The burden of visual truth: the role of photojournalism in mediating reality. New Jersey: Lawrence Erlbaum Associates; London: Publishers, 2001.

PORTO ALEGRE, Maria Sylvia. Reflexões sobre iconografia etnográfica: por uma hermenêutica visual. In: FELDMANBIANCO, Bela; LEITE, Míriam L. Moreira. Desafios da imagem: fotografia, iconografia e vídeo nas Ciências Sociais. 2. ed. Campinas, SP: Papirus, 2001. p. 75-112.

SOUSA, Jorge Pedro. Fotojornalismo: introdução à história, às técnicas e à linguagem da fotografia na imprensa. Florianópolis: Letras Contemporâneas, 2004.

TAVARES, Frederico de Mello Brandão; VAZ, Paulo Bernardo Ferreira. Fotografia jornalística e mídia impressa: formas de apreensão. Revista FAMECOS, Porto Alegre, n. 27, p. 125-138, ago. 2005. Disponível em: http://revistaseletronicas.pucrs.br/ojs/ index.php/revistafamecos/article/view/3329. Acesso em: 5 out. 2018.

VILCHES, Lorenzo. Teoría de la imagen periodística. Barcelona: Paidós Editora, 1993.

WOLF, Francis. Por trás do espetáculo: o poder das imagens. In: NOVAES, Adauto (org.). Muito além do espetáculo. São Paulo: Editora Senac, 2004. p. 16-45. 